\title{
A Relação entre Índices do Mercado Acionário e Taxas de Câmbio: evidências empíricas na América Latina
}

\author{
Bruno Pontes Renault ${ }^{1}$ \\ Filipe Pollis de Carvalho ${ }^{2}$ \\ Vinicius Mothé Maia ${ }^{3}$ \\ Antonio Carlos Figueiredo ${ }^{4}$ \\ Marcelo Cabús Klotzle
}

\section{Resumo}

O presente artigo tem como objetivo estudar a relação entre os retornos de índice de mercado de ações e taxas de câmbio de seis países da América Latina. De acordo com a abordagem do portfólio, ambas as variáveis devem ser negativamente correlacionadas. Tendo em vista que a regressão linear capta a relação linear média, não apresentando resultados satisfatórios, uma regressão quantílica foi usada para verificar essa relação em diferentes condições de mercado. Os resultados evidenciam um padrão no mercado latino americano, na qual a relação negativa entre as variáveis estudadas é mais pronunciada em momentos de forte desvalorização cambial.

Palavras-chave: mercado cambial; mercado acionário; América latina; regressão quantílica.

\section{The relationship between stock price index and exchange rate: empirical evidences from}

\section{Latin America}

\begin{abstract}
The present paper aims to study the relationship between stock price index returns and exchange rate of six Latin American countries. According to the portfolio balance effect, both variables are supposed to be negatively correlated. Since the linear regression results are not satisfactory, a quantile regression is made to verify these relationship under different market conditions. The results show a pattern in these Latin American markets, where the negative relation between the studied variables is more pronounced when the exchange rate is very high.
\end{abstract}

Keywords: exchange rate market; stock market; Latin America; quantile regression.

\section{INTRODUÇÃO}

Este trabalho buscou avançar no conhecimento acerca da existência de relação entre índices amplos do mercado acionário e a taxa de câmbio. Especificamente, foi estudada a associação entre a cotação de taxas de câmbio e o retorno dos mercados acionários na

\footnotetext{
${ }^{1}$ Mestre em Administração. IAG/PUC-Rio. brunoprenault@gmail.com

${ }^{2}$ Mestre em Administração e Analista Codemig. Codemig. fpollis@ gmail.com

${ }^{3}$ Doutorando em Administração IAG/PUC-Rio e Professor do curso de Ciências Contábeis FACC/UFRJ. viniciusmothemaia@yahoo.com.br

${ }^{4}$ Doutor em Economia. Prof. Quadro Principal IAG/ PUC-Rio. figueiredo@iag.puc-rio.br

${ }^{5}$ Doutor em Economia. Prof. Quadro Principal IAG/ PUC-Rio. klotzle@iag.puc-rio.br
} 
América Latina. Os países contemplados na análise foram: Argentina, Brasil, Chile, Colômbia, México e Peru.

Tanto os índices acionários quanto a taxa de câmbio são variáveis importantes na definição do crescimento e no desenvolvimento dos países. Diversos trabalhos abordaram essa temática em diferentes mercados, como: o norte-americano (Aggarwal, 1981; Bahmani e Sohrabian, 1992; Ratner, 1993; Kim, 2003), economias avançadas como Canadá, França e Alemanha (Ajayi e Mougoué, 1996), mercado asiático (Ibrahim e Aziz, 2003; Tsai, 2012) e o mercado brasileiro (Tabak, 2006).

Por não haver trabalhos publicados no tema com dados referentes à América Latina, busca-se preencher esse espaço e assim obter mais informações para a compreensão do quadro teórico geral. Tendo em vista que esse mercado ainda apresenta grandes oportunidades de crescimento e contempla parte significativa da população mundial, mostra-se relevante o preenchimento dessa lacuna no conhecimento quanto à relação entre duas importantes variáveis macroeconômicas.

É oportuno definir a taxa de câmbio. Ela serve como referência do custo de uma dada moeda em relação a outra qualquer. Constitui o preço de uma moeda estrangeira medido em unidades em relação à moeda nacional. A moeda estrangeira mais utilizada como parâmetro é o dólar norte-americano devido a sua maior liquidez. Uma alta na taxa de câmbio significa que são necessárias mais unidades da moeda doméstica para a compra da estrangeira, isto é, há uma depreciação da moeda doméstica. Por outro lado, uma baixa na taxa de câmbio significa menos unidades monetárias necessárias para a compra de uma unidade de moeda estrangeira; há uma apreciação da moeda doméstica (BRIGHAM e EHARDT, 2006).

Destaca-se que não há consenso na literatura brasileira ou internacional quanto ao real relacionamento entre mercado acionário e câmbio. Em linhas gerais, há duas correntes de pensamento: Abordagem Tradicional (AGGARWAL, 1981) e Abordagem do Portfólio (BAHMANI-OSKOOE e SOHRABIAN, 1992).

A Abordagem Tradicional examina o efeito que as variações na taxa de câmbio causam nos índices do mercado acionário, de modo a modificar o valor dos ativos e passivos das empresas domésticas e multinacionais (AGGARWAL, 1981). O autor ilustra como exemplo que uma eventual desvalorização da moeda doméstica favoreceria o aumento das exportações das empresas e, por fim, a valorização de suas ações. Em outras palavras, um aumento da taxa de câmbio provocaria também uma simultânea subida do preço das ações, o que caracteriza uma relação direta entre estas duas variáveis. Por outro lado, empresas com passivos em moda estrangeira sofreriam o efeito inverso, tendo em vista que suas dívidas ReFAE - Revista da Faculdade de Administração e Economia, v. 9, n. 2, p. 132-149, 2019 
seriam maiores. Nesse caso, a variação das suas ações não seria de simples determinação.

A Abordagem do Portfólio, por sua vez, tem como base um raciocínio oposto: as variações dos preços das ações de empresas de determinado país teriam a capacidade de impactar na taxa de câmbio (BAHMANI-OSKOOE e SOHRABIAN, 1992). Em um cenário de expectativa de valorização das ações, os investidores estrangeiros aumentariam o fluxo de dinheiro para o país, acarretando aumento da demanda por moeda doméstica e, finalmente, queda da taxa de câmbio. Dessa forma, a taxa de câmbio teria relação negativa em relação aos preços das ações. No entanto, de acordo com Tsai (2012), isso somente acontece quando o mercado de capitais é volátil o suficiente, do contrário o mercado cambial não seria influenciado ou teria influência restrita. Somente quando a oportunidade de lucrar é julgada grande suficiente é que grandes quantidades de capital estrangeiro podem influenciar o mercado cambial.

Sendo assim, o objetivo do artigo foi verificar como é a relação entre os preços das ações, representado por seu índice amplo, e taxa de câmbio, sendo essa relação: existente (negativa ou positiva) ou inexistente. Assim, será possível constatar se há maior proximidade com a abordagem tradicional ou do portfólio e, ainda, entender se o mercado acionário impacta ou é impactado pelo mercado cambial.

Quanto ao método de pesquisa, foi adotada a regressão quantílica a fím de detectar relações entre índices acionários e câmbio em diferentes condições de mercado. Nessa abordagem, a associação entre as variáveis foi analisada sob diferentes quartis, permitindo observar a existência ou não da relação entre as variáveis em cenários de forte valorização ou desvalorização cambial.

Os resultados evidenciam que a relação entre o mercado acionário e o cambial é inversamente proporcional, ou seja, uma valorização cambial é normalmente acompanhada por uma alta no mercado acionário (e vice-versa). Essa relação é mais intensa quando ocorrem variações extremas, isso quer dizer, a relação se torna mais forte em momentos de acentuada valorização ou desvalorização cambial.

Sem contar introdução, o trabalho segue dividido da seguinte forma: a seção 2 contempla a revisão de literatura e as descobertas verificadas em pesquisas anteriores. A seção 3 ilustra o método de pesquisa adotado. A seção 4 descreve os resultados gerados pela aplicação do método. A seção 5 sintetiza as principais conclusões do artigo e apresenta sugestões de pesquisas futuras.

\section{REFERENCIAL TEÓRICO}

ReFAE - Revista da Faculdade de Administração e Economia, v. 9, n. 2, p. 132-149, 2019 
A adoção do regime de câmbio flutuante é, para alguns países da América Latina, uma decisão tomada há poucos anos. Na década de 1990, Brasil e México deixaram de utilizar o regime de bandas cambiais e adotaram o regime de câmbio flutuante. A Argentina, por sua vez, deixou de ter o controle cambial sistemático por parte do governo mais tarde, em 2002.

Tendo em vista o término do sistema de câmbio fixo nos países contemplados nesta pesquisa, é possível estudar com mais clareza a relação entre os mercados de câmbio e de ações, variáveis econômicas de suma importância para o desenvolvimento das nações. Ressalta-se que não há consenso se a taxa de câmbio impacta o mercado de ações ou o contrário. Há pesquisas passadas que indicam as duas possibilidades.

De acordo com Aggarwal (1981), as variações na taxa de câmbio geram mudanças no mercado acionário. Esta é a abordagem tradicional ou do comércio internacional, na qual é prevista uma relação positiva entre tais variáveis. Como exemplo, uma queda no valor da moeda local está correlacionada a uma queda no valor das ações.

Por outro lado, Bahmani e Sohrabian (1992) analisaram a influência das variações nos preços das ações na taxa de câmbio. Eles ilustraram a abordagem do portfólio, em que é verificada uma relação negativa entre as duas variáveis. Em outras palavras, uma valorização das ações aumentaria a riqueza dos investidores domésticos, o que levaria ao aumento da demanda pela moeda nacional e, por fim, à valorização do câmbio.

No que concerne aos países desenvolvidos, há diversas pesquisas realizadas quanto ao tema. O trabalho detectado com maior abrangência envolvendo tais países foi o de Ajayi e Mougoué (1996). Eles abordaram os mercados canadense, francês, alemão, italiano, japonês, holandês, britânico e norte-americano. Ajayi e Mougoué (1996) adotaram um modelo de correção de erro e concluíram haver correlações negativas no curto prazo e correlações positivas no longo prazo entre os mercados acionário e cambial.

Analogamente, Kim (2003) utilizou o modelo de correção de erro e cointegração multivariada para analisar a relação entre câmbio e ações nos Estados Unidos entre 1974 e 1998. Os resultados indicaram a existência de correlação negativa entre preço das ações e cotação do câmbio tanto no curto quanto no longo prazo.

Ratner (1993) quis validar a ideia de que a desvalorização do dólar em relação a outras moedas afetaria favoravelmente o preço das ações norte-americanas, haja vista o aumento das exportações e o aumento da demanda interna por bens importados. A análise de regressão e o teste de cointegração concluíram que a crença de uma ligação sistemática entre o valor do câmbio e reações do mercado é espúria. A incapacidade de vincular tais variáveis suportaria e existência de um mercado eficiente. 
Já quanto aos países emergentes, os trabalhos foram desenvolvidos algum tempo após o início nos mercados desenvolvidos. Tsai (2012) analisou diversas economias asiáticas a partir do método da regressão quantílica e os resultados indicaram que a existência de relação negativa entre os mercados de ações e cambial é mais evidente quando as taxas de câmbio estão extremamente baixas ou altas.

Ibrahim e Aziz (2003) se debruçaram sobre o mercado da Malásia e usaram dados mensais dos preços das ações e taxas de câmbio referentes ao período compreendido entre 1977 e 1998. Assim como Kim (2003), concluíram haver relação negativa entre as duas variáveis. Pôde-se, então, concluir que quando o câmbio se aprecia, o mercado acionário tende a sofrer perdas.

Quanto ao mercado brasileiro, Tabak (2006) coletou dados referentes aos anos entre 1994 e 2002 e não encontrou relação de longo prazo entre os mercados cambial e acionário. Todavia, o teste de causalidade linear de Granger entre as variáveis levou a resultados em linha com a abordagem do portfólio, em que o preço das ações é correlacionado negativamente com a taxa de câmbio. Por outro lado, a aplicação da do teste de causalidade não linear de Granger implicou em resultado alinhado à abordagem tradicional, em que a taxa de câmbio impacta no preço das ações.

Em geral, não há consenso na literatura quanto à existência de relações de curto ou longo prazo entre taxa de câmbio e preço das ações. Os resultados dependem da metodologia de tratamento dos dados a ser aplicada, das características do mercado, da periodicidade dos dados, entre outros fatores.

Dada à inexistência de estudos passados que se propuseram a estudar a relação entre essas importantes variáveis financeiras no mercado latino americano, buscou-se preencher essa lacuna e contribuir para o avanço no conhecimento quanto ao tema. Procura-se, também, auxiliar investidores nacionais e estrangeiros na decisão de alocar recursos em países da América Latina.

\section{METODOLOGIA}

O presente artigo se utiliza de dados mensais de retorno de índices de mercado de capitais de Argentina, Brasil, Chile, Colômbia, México e Peru. São eles, respectivamente: Merval, Ibovespa, IPSA, COLCAP, Mexbol e Spblpgpt. Utilizou-se também dados mensais de variação das taxas de câmbio em relação ao dólar americano desses mesmos países. O software R foi o escolhido para posterior análise e tratamento estatístico dos dados.

Cada país apresenta certa particularidade histórica que faz com que o período de coleta ReFAE - Revista da Faculdade de Administração e Economia, v. 9, n. 2, p. 132-149, 2019 
de dados seja diferente. A série da Argentina, por exemplo, somente apresenta dados consistentes a partir de 2002, quando o câmbio se tornou flutuante. O mesmo ocorre com o Brasil a partir de 1999, com o término das bandas cambiais e início do regime de câmbio flutuante. No caso da Colômbia, a série é iniciada em 2002 devido à disponibilidade de dados do índice acionário começar nessa data. Os dados Chile, México e Peru não apresentaram nenhum padrão que pudesse comprometer os resultados e, portanto, suas séries têm início em 1990, 1994 e 1992, respectivamente.

De posse de cada uma das séries, calculou-se o log retorno de cada uma das séries e, antes de prosseguir para a regressão, foram calculados os testes de raiz unitária. Quando uma variável tem a presença de uma raiz unitária, a pressuposição de que sua média e a variância são constantes ao longo do tempo é violada; os resultados obtidos com a utilização de modelos econométricos se encontram comprometidos, pois a regressão é considerada espúria (GRANGER e NEWBOLD, 1974).

Um importante teste de raiz unitária é o Dickey-Fuller (1979), o qual estima a seguinte auto regressão:

$$
\nabla y_{t}=(\rho-1) y_{t-1}+\varepsilon_{1}
$$

ou:

$$
\nabla \mathrm{y}_{t}=\gamma y_{t-1}+\varepsilon_{1}
$$

Onde $\nabla=\left(y_{t}-y_{t-1}\right)$ é o operador diferença e $\gamma=\rho-1$. Nesse caso, a hipótese nula $H_{0}$ é de que exista pelo menos uma raiz unitária. Logo, a variável não é estacionária e $\gamma=0$. Por sua vez, a hipótese alternativa $\left(H_{1}\right)$ é que a variável seja fracamente estacionária, nesse caso não há nenhuma raiz unitária e consequentemente $\gamma<0$.

Alternativamente, o teste Dickey-Fuller (DF) pode ser conduzido utilizando-se a seguinte expressão:

$$
\mathrm{y}_{\mathrm{t}}=\rho y_{t-1}+s_{1}
$$

Nesse caso, testa-se a hipótese nula de que $\rho=1$, isto é, tenha uma raiz unitária contra a hipótese alternativa de que não tenha raiz unitária, ou seja, $\rho<1$.

A equação pode ser ampliada para incorporar a presença ou não de intercepto ou tendência, isto é, o procedimento Dickey-Fuller permite que se teste a existência ou não de raiz unitária naqueles casos em que seja necessária a introdução ou não de constante ou tendência. $\mathrm{O}$ teste para ambos os casos é conduzido de maneira semelhante ao apresentado 
acima. A diferença é que no caso em que seja necessária a introdução de uma constante, a auto-regressão a ser utilizada é a seguinte:

$$
\nabla \mathrm{y}_{\mathrm{t}}=\alpha+\gamma y_{t-1}+\varepsilon_{1}
$$

Onde $\alpha$ é o intercepto. Caso seja necessária a presença da tendência e do intercepto, a equação a ser utilizada é a seguinte:

$$
\nabla y_{t}=\alpha+\beta t+\gamma y_{t-1}+\varepsilon_{1}
$$

Sendo que, o termo $t$ representa a tendência linear.

O teste Dickey-Fuller parte da pressuposição de que os termos de erros nas equações acima são identicamente e independentemente distribuídos, isto é, não apresentam autocorrelação. Em função disso, o teste Dickey-Fuller foi ampliado de forma a incorporar defasagens em relação à variável que está sendo analisada (Said e Dickey, 1984). Ao proceder dessa maneira obtém-se o teste Dickey-Fuller Aumentado (ADF), o qual adiciona à equação a própria variável defasada e diferenciada, assumindo o seguinte aspecto:

$$
\nabla y_{t}=\alpha+\beta t+\gamma y_{t-1}+\varepsilon_{1}+\sum_{j=1}^{p+1} \rho_{j+1} \nabla y_{t-j} \varepsilon_{1}
$$

A principal vantagem do teste $\mathrm{ADF}$ em relação ao DF é que, ao introduzir um número suficiente de defasagens, garante-se que os resíduos não apresentem autocorrelação.

Por sua vez, o teste criado por Denis Kwiatkowski, Peter C. B. Phillips, Peter Schmidt e Yongcheol Shin (1992), denominado teste KPSS, tem por finalidade determinar a estacionariedade de uma série temporal. Assume como hipótese nula a estacionariedade da série. O teste é definido como:

$$
L M=\sum_{t=1}^{N} \frac{s_{t}^{2}}{N^{2} \sigma_{\varepsilon}^{2}}
$$

Onde $N$ é o número de observações, $S_{t}$ é a soma parcial dos resíduos e $\sigma_{\varepsilon}^{2}$ um estimador para a variância dos erros nesta regressão.

Após a verificação da estacionariedade das séries de retorno, calculou-se a regressão exposta na equação 8 , primeiramente pelo método de mínimo quadrados ordinários e em seguida pelo método da regressão quantílica, apresentado a seguir.

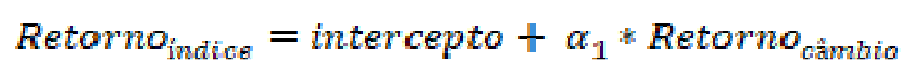

ReFAE - Revista da Faculdade de Administração e Economia, v. 9, n. 2, p. 132-149, 2019 
O método de estimação conhecida por regressão quantílica foi apresentado na literatura especializada por Koenker e Basset (1978). Desde então tem motivado a atenção de pesquisadores e servido de instrumental para diversas constatações empíricas. A grande vantagem é que a estimação pelo método de regressão quantílica permite identificar as variações inter e intra quartis, o que o método de regressão por mínimos quadrados ordinários (MQO) não comporta, pois é baseado na média da distribuição condicional.

Seja $y_{i}$ uma variável aleatória real, $x_{i}$ uma constante que representa um vetor $\mathrm{k}$ x 1 de regressores, $\beta$ é o coeficiente do modelo e $u_{i}$. O objetivo da regressão quantílica é estimar $\beta$ para diferentes quartis condicionais. Tem-se:

$$
y_{i}=x_{i} \beta+u_{i}
$$

A partir da definição, os quartis podem ser reformulados como solução de um problema simples de programação linear. Sendo $\theta$-ésimo quartil para $0<\theta<1$, tem-se:

$$
Q_{\theta}\left(y_{i} \mid x_{i}\right)=x_{i} \beta(\theta)
$$

A equação da regressão quantílica fica definida:

$$
\min _{\beta}\left[\theta \sum_{y_{i} \sum \beta x_{i}}\left|y_{i}-\beta x_{i}\right|+(1-\theta) \Sigma_{y_{i} \leq \beta x_{i}}\left|y_{i}-\beta x_{i}\right|\right]
$$

Onde $x_{i} \beta$ é uma aproximação do $\theta$-ésimo quartil de $y_{i}$. Quando $\theta$ se aproxima de zero ou um, $x_{i} \beta$ indica o comportamento de $y_{i}$ nos extremos da distribuição condicional.

\section{RESULTADOS}

O primeiro contato com os dados é por meio da estatística descritiva das séries temporais de retorno mensal dos índices e variações mensais da taxa de câmbio conforme a tabela 1:

Tabela 1 - Estatística Descritiva dos Dados

\begin{tabular}{cccccccc}
\hline Variável & País & Observ. & Média & Mediana & Desvio-padrão & Assimetria & Curtose \\
\hline Índice & Argentina & 170 & 0,019925 & 0,020575 & 0,096829 & $-0,6709$ & 2,385701
\end{tabular}


ReFAE - Revista da Faculdade de Administração e Economia

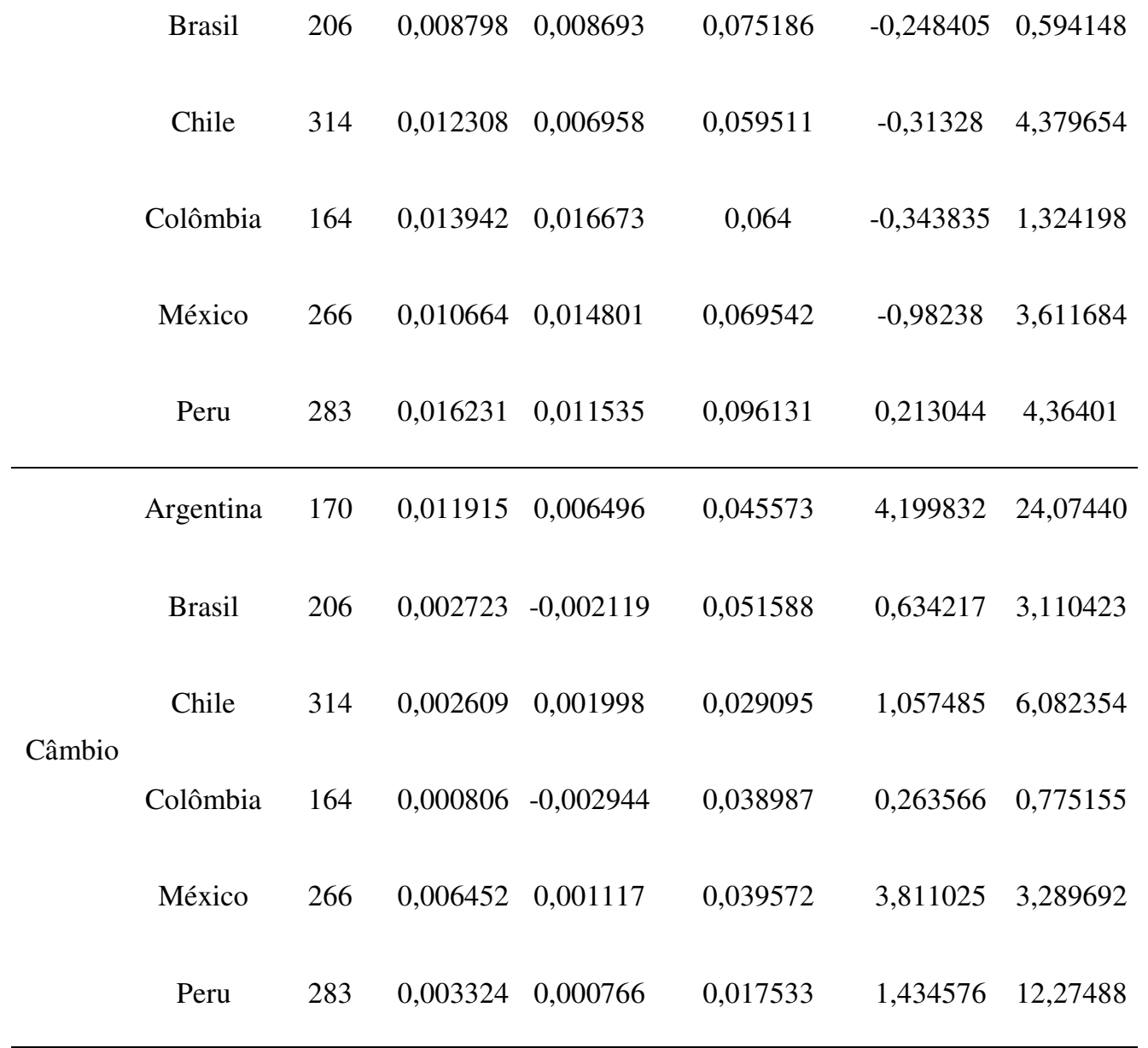

Fonte: elaborado pelos autores.

Como destaques em relação aos índices, registra-se o retorno médio de aproximadamente $2 \%$ do índice Merval contra o retorno inferior a $1 \%$ do índice Ibovespa. Quanto à assimetria, todas apresentaram coeficientes negativos, ou seja, maior tendência de desvios negativos do que positivos em relação à média, à exceção do índice peruano.

Em seguida, a tabela 1 contempla análises descritivas em relação ao câmbio. O retorno médio desta variável foi positivo para todos os países, tendo a Argentina o maior valor e a Colômbia o menor. A assimetria do retorno cambial foi positiva em todos os grupos, o que indica elevada concentração de ocorrências em valores baixos e maior tendência de desvios positivos em relação à média. Por fim, os indicadores de curtose foram superiores a $3 \mathrm{em}$ todos os países à exceção da Colômbia. Tal fato mostra que as distribuições dos retornos cambiais são leptocúrticas.

Antes de empreender o modelo empírico, é necessário que as séries sejam estacionárias, de modo que as variáveis não podem ter raiz unitária, ou seja, que sua média e variância não sejam constantes ao longo do tempo. Portanto, os testes de raiz unitária ADF e 
KPSS foram aplicados para verificar a estacionariedade das séries. O teste ADF tem como hipótese nula de que a série tenha raiz unitária (não sendo estacionário), sendo assim necessário rejeitar a hipótese nula. O teste KPSS, por sua vez, tem como hipótese nula de que a série é estacionária, sendo assim necessário não rejeitar a hipótese nula.

Os resultados dos testes ADF e KPSS são apresentados na tabela 2:

Tabela 2 - Testes de raiz unitária ADF e KPSS

\begin{tabular}{llll}
\hline Variável & País & ADF & KPSS \\
\hline \multirow{4}{*}{ Indice } & Argentina & $<0,01$ & $>0,10$ \\
& Brasil & $<0,01$ & $>0,10$ \\
& Chile & $<0,01$ & 0,02 \\
& Colômbia & $<0,01$ & $>0,10$ \\
& México & $<0,01$ & $>0,10$ \\
& Peru & $<0,01$ & 0,05 \\
& & $<0,01$ & $>0,10$ \\
& Argentina & $<0,01$ & $>0,10$ \\
& Brasil & $<0,01$ & $>0,10$ \\
& Chile & $<0,01$ & $>0,10$ \\
& Colômbia & $<0,01$ & 0,09 \\
& México & $<0,01$ & 0,01 \\
\hline Pâmbio & Peru & $<$
\end{tabular}

Fonte: elaborado pelos autores.

Os resultados dos testes de raiz unitária evidenciam que as variáveis cumpriram o requisito de estacionariedade. Apesar de algumas discrepâncias entre os métodos ADF e KPSS, decidiu-se que tanto as variáveis índice quanto câmbio cumpriram o pré-requisito de não existência de raiz unitária.

A fim de empreender uma análise preliminar da relação entre os mercados de capitais e o cambial, foi feita uma regressão linear entre os retornos dos índices de mercado e taxa de câmbio. Haja vista que esse trabalho adota a abordagem do portfólio, na qual um retorno positivo no mercado acionário tem como contrapartida uma valorização no mercado cambial, adota-se o retorno do índice de mercado como variável independente e a variação das taxas cambiais como variável dependente.

Os resultados são apresentados na tabela 3. Todos os coeficientes $\alpha_{1}$ de relação entre as variáveis estudadas são negativos e significantes, com exceção da Argentina e Peru. Isso significa que um aumento no retorno de índice de mercado é 
acompanhado uma queda subsequente na taxa de câmbio, ou seja, uma apreciação da taxa. $\mathrm{O}$ raciocínio contrário é análogo.

Os resultados confirmam a abordagem do portfólio, na qual é pressuposta uma relação negativa entre as variáveis, especialmente nos mercados latinos que experimentaram recentemente grandes fluxos de capital estrangeiro. No entanto, com exceção do Brasil, todas as demais regressões apresentaram $\mathrm{R}^{2}$ ajustado baixo.

Tabela 3 - Resultados das regressões lineares

\begin{tabular}{|c|c|c|c|c|c|c|}
\hline \multicolumn{7}{|c|}{ País } \\
\hline & \multicolumn{2}{|l|}{ Argentina } & \multicolumn{2}{|l|}{ Brasil } & \multicolumn{2}{|l|}{ Chile } \\
\hline & Coeficiente & $\begin{array}{l}\text { Nível signi- } \\
\text { ficância }\end{array}$ & Coeficiente & $\begin{array}{l}\text { Nível signi- } \\
\text { ficância }\end{array}$ & Coeficiente & $\begin{array}{c}\text { Nível signi- } \\
\text { ficância }\end{array}$ \\
\hline Intercepto & 0,012864 & $* * *$ & 0,00654 & $*$ & 0,003947 & $*$ \\
\hline$\alpha_{1}$ & $-0,047583$ & & $-0,429826$ & $* * *$ & $-0,108669$ & $* * *$ \\
\hline \multirow[t]{3}{*}{$\mathrm{R}^{2}$ ajustado } & 0,00433 & & 0,3895 & & 0,04636 & \\
\hline & Colômbia & & México & & Peru & \\
\hline & Coeficiente & $\begin{array}{l}\text { Nível signi- } \\
\text { ficância }\end{array}$ & Coeficiente & $\begin{array}{l}\text { Nível signi- } \\
\text { ficância }\end{array}$ & Coeficiente & $\begin{array}{l}\text { Nível signi- } \\
\text { ficância }\end{array}$ \\
\hline Intercepto & 0,004004 & & 0,008774 & $* * *$ & 0,003471 & $* *$ \\
\hline$a_{1}$ & $-0,229359$ & $* * *$ & $-0,217747$ & $* * *$ & $-0,009054$ & \\
\hline $\mathrm{R}^{2}$ ajustado & 0,1365 & & 0,1432 & & 0,001086 & \\
\hline
\end{tabular}

Nota: Nos casos em que foram detectados auto correlação temporal, através do teste de Durbin-Watson, ou heterocedasticidade, através do teste de Breusch-Pagan, o erro dos estimadores foi corrigido pela matriz HAC.

$*$, ** e *** corresponde à significância de $10 \%, 5 \%$ e $1 \%$ respectivamente.

Fonte: elaborado pelos autores.

Parte-se então para a reestimativa do modelo por meio de regressão quantílica. A tabela 4 evidencia como os resultados da regressão resultam em coeficientes que se alteram dependendo dos quartis. As figuras 1 a 6 plotam 9 pontos que representam os coeficientes estimados resultantes de regressões para cada quartil. Ilustra-se, portanto, como a distribuição com diferentes quartis revela uma relação entre o mercado cambial e o mercado acionário que muda quando a distribuição condicional se mostra heterogênea.

Tabela 4 - Resultados das regressões quantílicas

\begin{tabular}{ccccc}
\hline País & Quartil & Coeficiente & Limite superior (95\%) & Limite inferior (95\%) \\
\hline Argentina & 0,1 & $-0,04766$ & $-0,13141$ & 0,05783
\end{tabular}




\begin{tabular}{|c|c|c|c|c|}
\hline & 0,2 & $-0,0382$ & $-0,05923$ & 0,01497 \\
\hline & 0,3 & $-0,02272$ & $-0,04623$ & 0,01167 \\
\hline & 0,4 & $-0,02051$ & $-0,04454$ & 0,0107 \\
\hline & 0,5 & $-0,01176$ & $-0,03791$ & 0,00971 \\
\hline & 0,6 & $-0,00092$ & $-0,02412$ & 0,00783 \\
\hline & 0,7 & $-0,00549$ & $-0,02639$ & 0,01447 \\
\hline & 0,8 & $-0,01508$ & $-0,05528$ & 0,02471 \\
\hline & 0,9 & $-0,09036$ & $-0,13449$ & $-0,02592$ \\
\hline & 0,1 & -0.40167 & -0.45492 & -0.30038 \\
\hline & 0,2 & -0.36727 & -0.45348 & -0.30297 \\
\hline & 0,3 & -0.39245 & -0.46432 & -0.29644 \\
\hline & 0,4 & -0.35471 & -0.42693 & -0.27936 \\
\hline Brasil & 0,5 & -0.33336 & -0.43559 & -0.25903 \\
\hline & 0,6 & -0.36792 & -0.39521 & -0.25620 \\
\hline & 0,7 & -0.34985 & -0.41556 & -0.30238 \\
\hline & 0,8 & -0.39515 & -0.50858 & -0.32229 \\
\hline & 0,9 & -0.45496 & -0.60879 & -0.41134 \\
\hline & 0,1 & -0.06843 & -0.12799 & -0.00523 \\
\hline & 0,2 & -0.10236 & -0.16829 & -0.04053 \\
\hline & 0,3 & -0.08076 & -0.15697 & -0.02896 \\
\hline & 0,4 & -0.06012 & -0.12029 & -0.02052 \\
\hline Chile & 0,5 & -0.04863 & -0.13056 & -0.01847 \\
\hline & 0,6 & -0.06052 & -0.11395 & -0.02047 \\
\hline & 0,7 & -0.08340 & -0.14319 & -0.02855 \\
\hline & 0,8 & -0.10487 & -0.13148 & -0.06358 \\
\hline & 0,9 & -0.14896 & -0.19200 & -0.06885 \\
\hline & 0,1 & -0.18002 & -0.38338 & 0.00018 \\
\hline & 0,2 & -0.17718 & -0.28855 & -0.11238 \\
\hline & 0,3 & -0.23290 & -0.27218 & -0.12786 \\
\hline & 0,4 & -0.22162 & -0.28011 & -0.12899 \\
\hline Colômbia & 0,5 & -0.21145 & -0.28467 & -0.10645 \\
\hline & 0,6 & -0.17054 & -0.33461 & -0.13491 \\
\hline & 0,7 & -0.22261 & -0.28813 & -0.14958 \\
\hline & 0,8 & -0.25200 & -0.31697 & -0.21525 \\
\hline & 0,9 & -0.32418 & -0.36802 & -0.18777 \\
\hline México & 0,1 & -0.19383 & -0.23715 & -0.07561 \\
\hline
\end{tabular}




\begin{tabular}{ccccc}
0,2 & -0.15917 & -0.21952 & -0.09374 \\
0,3 & -0.14661 & -0.18796 & -0.11037 \\
0,4 & -0.14175 & -0.21416 & -0.10904 \\
0,5 & -0.15948 & -0.22027 & -0.11494 \\
0,6 & -0.16214 & -0.25161 & -0.11946 \\
0,7 & -0.18018 & -0.23003 & -0.11917 \\
0,8 & -0.19590 & -0.23780 & -0.13184 \\
0,9 & -0.26210 & -0.32669 & -0.19815 \\
\hline 0,1 & -0.04678 & -0.06401 & 0.01949 \\
0,2 & -0.02963 & -0.05400 & -0.00110 \\
0,3 & -0.02514 & -0.04992 & -0.00740 \\
0,4 & -0.02027 & -0.04516 & -0.01133 \\
0,5 & -0.03244 & -0.04486 & -0.01285 \\
0,6 & -0.03506 & -0.05398 & -0.01477 \\
0,7 & -0.02413 & -0.04983 & -0.00175 \\
0,8 & -0.01327 & -0.03659 & 0.00534 \\
0,9 & -0.01417 & -0.02387 & -0.00069 \\
\hline
\end{tabular}

Fonte: elaborado pelos autores.

Com exceção do Peru, os demais países apresentam um padrão relativamente similar, no qual os coeficientes tendem a ser mais negativos quando as variações das taxas de câmbio são extremamente altas. É possível visualizar pelas figuras 1 a 6 que os valores estimados dos coeficientes são mais negativos nos respectivos últimos quartis em relação aos demais quartis.

Figura 1 - Coeficientes obtidos para diferentes quartis da Argentina

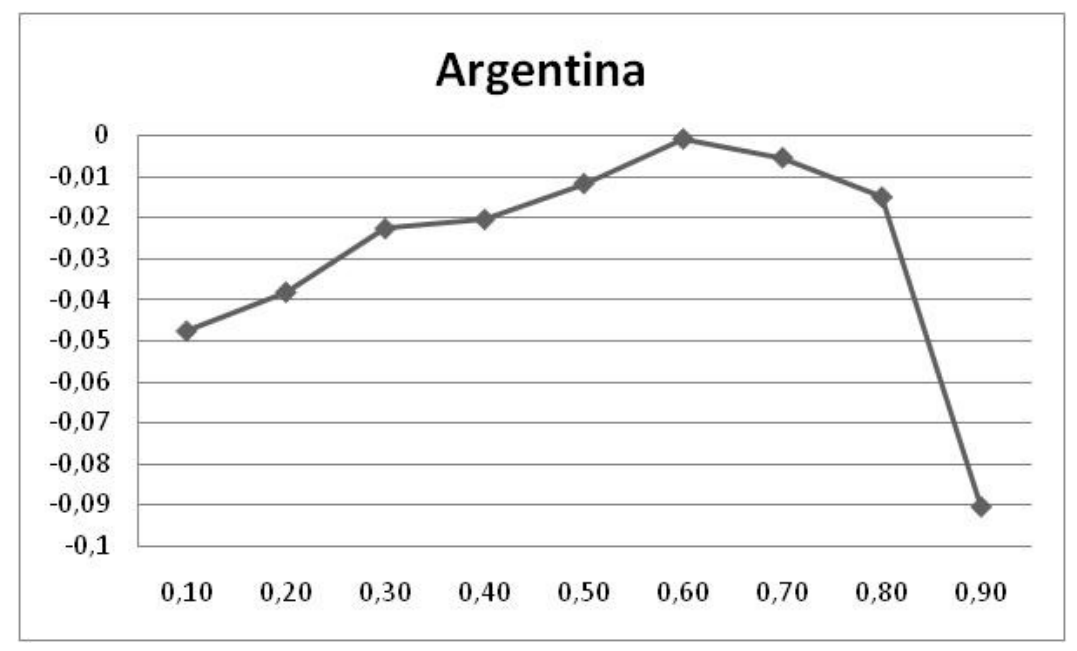

Fonte: elaborado pelos autores. 
Figura 2 - Coeficientes obtidos para diferentes quartis do Brasil

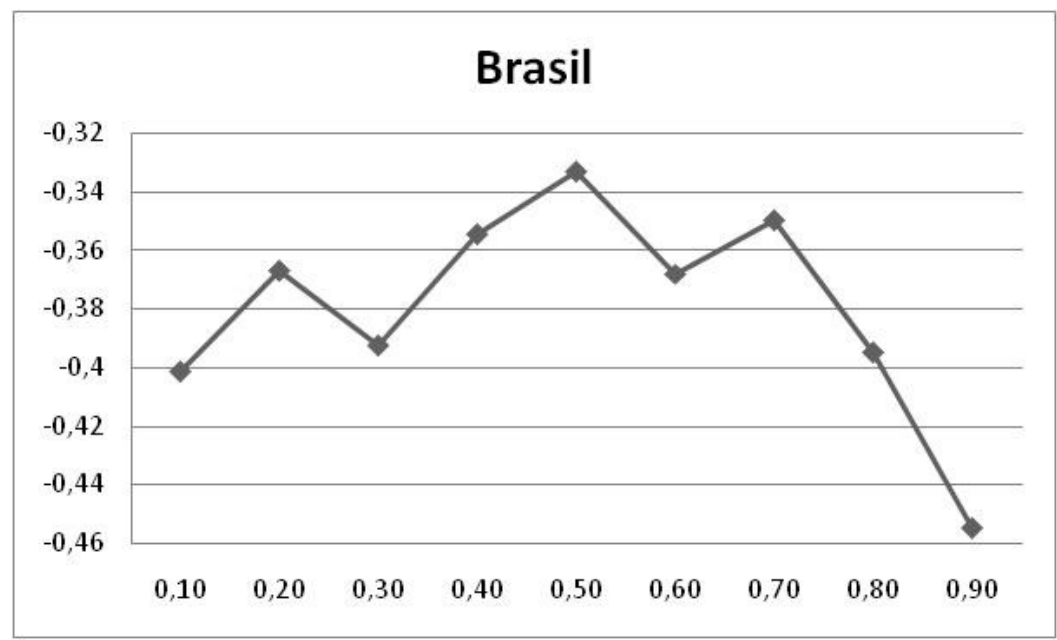

Fonte: elaborado pelos autores.

Figura 3 - Coeficientes obtidos para diferentes quartis do Chile

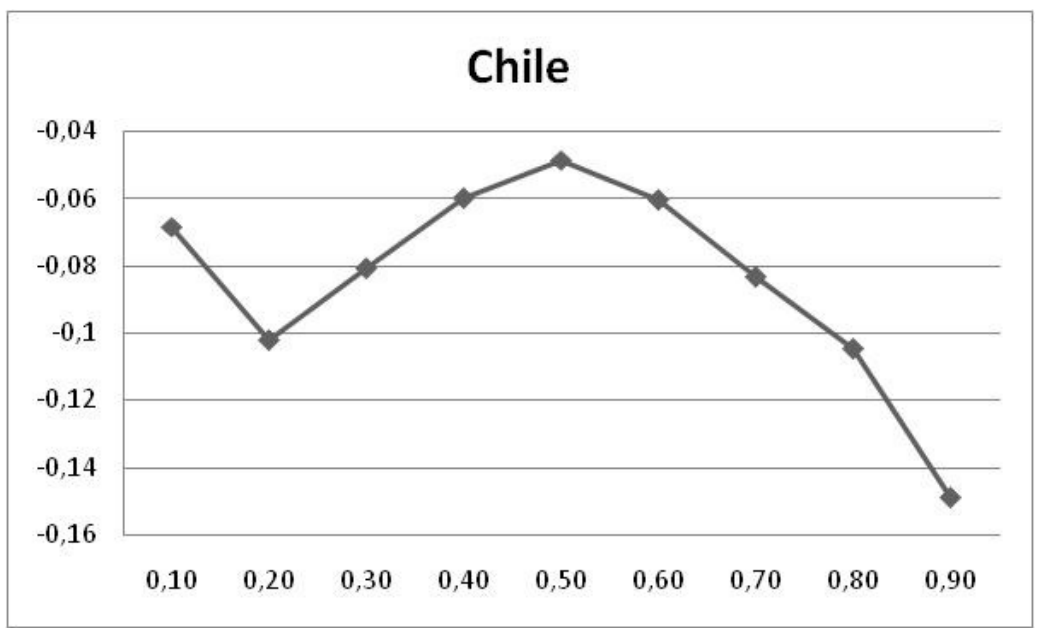

Fonte: elaborado pelos autores.

Figura 4 - Coeficientes obtidos para diferentes quartis da Colômbia 


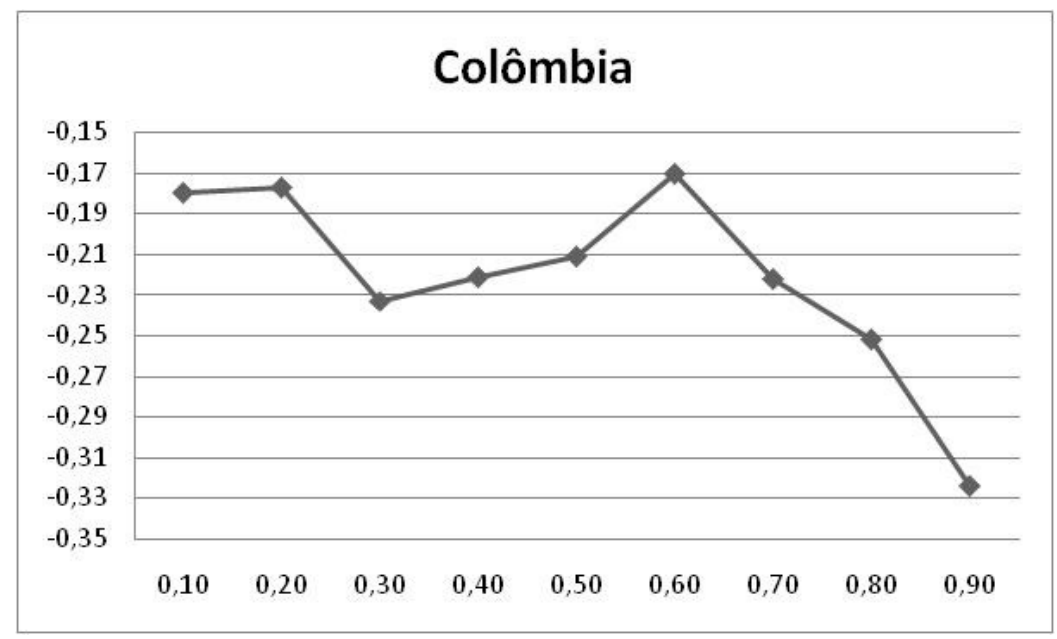

Fonte: elaborado pelos autores.

Figura 5 - Coeficientes obtidos para diferentes quartis do México.

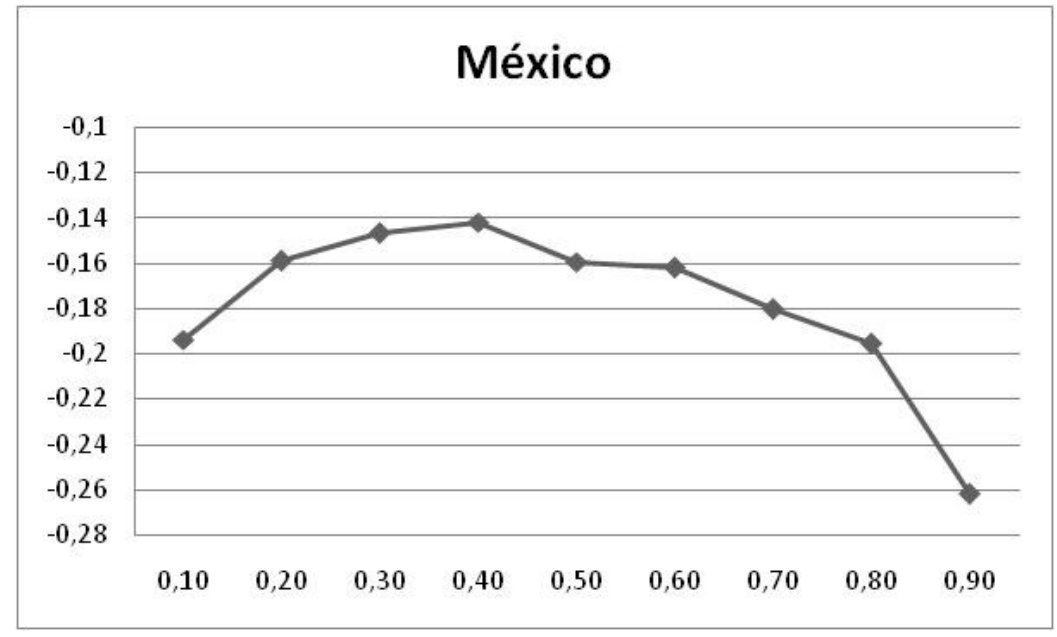

Fonte: elaborado pelos autores.

Figura 6 - Coeficientes obtidos para diferentes quartis do Peru

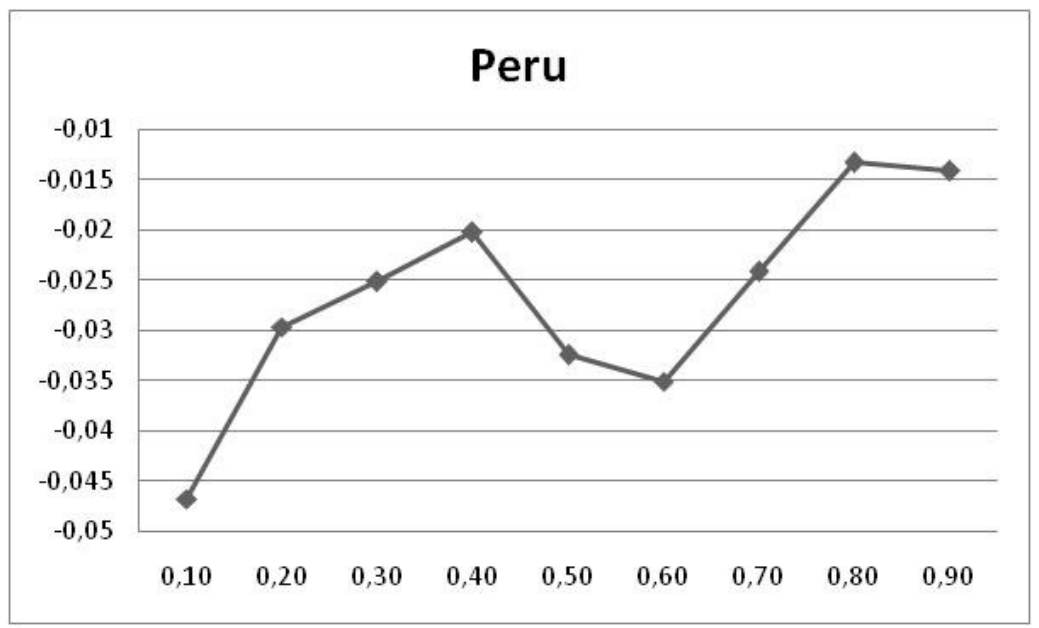

Fonte: elaborado pelos autores.

O coeficiente da Argentina no último quartil é -0,09036, diferente do coeficiente de - 
0,01176 do quinto quartil; o coeficiente do Brasil é -0.45496, o qual é mais negativo do que 0.33336 do quinto quartil; o mesmo vale para o Chile (-0.14896 comparado a -0.04863), Colômbia (-0.32418 comparado a -0.21145) e México (-0.26210 comparado a -0.15948).

É notável também que o segundo coeficiente mais negativo em termos absolutos é dado pelo primeiro quartil nos casos de Argentina, Brasil, México e Peru (o segundo quartil no caso do Chile). Ou seja, os quartis extremos revelam coeficientes mais negativos e presença de uma relação negativa maior, embora em uma escala consideravelmente maior para o último quartil do que para o primeiro. Infere-se, portanto, que a relação entre índices de mercado e taxas de câmbio é negativa, como concluído pela regressão linear feita previamente.

No entanto, essa relação é assimétrica: ela é maior em termos absolutos nos extremos, particularmente mais forte quando as taxas de câmbio são mais altas. Conclui-se pelos resultados que o mercado cambial na América Latina se mostra sensível a mudanças verificadas no mercado acionário. Particularmente, quando o último apresenta queda, a taxa de câmbio deprecia numa escala bem elevada, isto é, a taxa de câmbio se eleva numa escala maior.

De modo análogo, quando o mercado acionário apresenta ganhos, a taxa de câmbio se aprecia, embora numa escala menor como evidenciado pela regressão quantílica. É importante salientar novamente que a abordagem do portfólio não é sempre verificada na prática. É necessário que o mercado acionário seja volátil para que haja impacto significativo no mercado cambial. Se existir oportunidade clara de lucro, quantidades de capital relevantes podem entrar e sair do mercado, exercendo influência no mercado de câmbio. No caso dos mercados da América Latina, isso parece ser particularmente aplicável, tendo em vista que experimentaram grandes fluxos de capital estrangeiro nas últimas décadas.

\section{CONCLUSÃO}

O artigo busca entender como é a relação entre os preços das ações, representado por seu índice amplo, e variações na taxa de câmbio. Foram utilizados dados mensais de retorno dos principais índices de mercado e variações mensais de taxas de câmbio de moedas da América Latina em relação ao dólar americano. A regressão linear confirma que a relação entre as duas variáveis é negativa, porém se mostra limitada ao somente prover a estimativa através das médias. Além disso, as regressões têm pouco poder explicativo.

Desse modo, foi aplicado o método da regressão quantílica. Os resultados evidenciam que, exceto o Peru, todos os cinco países apresentam um padrão, qual seja coeficientes mais 
negativos nos quartis extremos, especialmente nos quartis superiores nos quais o coeficiente é maior em termos absolutos. Os coeficientes negativos se mostram de acordo com a abordagem do portfólio, a qual postula que a queda da taxa de câmbio (apreciação), tem como consequência retornos positivos do mercado acionário. Os resultados estão de acordo com o estudo de Tsai (2012), no qual foram verificados coeficientes mais negativos quando as taxas de câmbio estão no extremo, tanto altas quanto baixas.

Como demonstrado pelos resultados da regressão quantílica, a escala na qual essa relação se mostra negativa varia dependendo de diferentes condições de mercado, haja vista que a abordagem do portfólio somente se materializa quando a oportunidade de lucro é clara para o investidor estrangeiro, quando grandes quantidades de capital entram e saem de um mercado, não existindo, portanto, em situações normais.

Tendo em vista que os mercados da América Latina constituem destinos para o capital estrangeiro, pois apresentam oportunidades de ganhos não encontrados em seus países de origem, os resultados alcançados pela regressão quantílica se mostram relevantes. Nesses países, a taxa de câmbio sofre maior influência quando há grande capital estrangeiro entrando (aumentando os retornos do mercado acionário e diminuindo a taxa de câmbio) e, especialmente, quando há fuga de capital (diminuindo os retornos e aumentando a taxa de câmbio) em uma escala maior.

Como sugestão para futuras pesquisas estaria a inclusão de dados referentes à entrada de capital estrangeiro de modo a enriquecer e reforçar as conclusões que esse artigo chegou. Ademais, é possível replicar o estudo para dados diários a fim de verificar se os resultados são diferentes em relação ao uso de dados mensais.

\section{REFERÊNCIAS BIBLIOGRÁFICAS}

AGGARWAL, R. Exchange rates and stock prices: a study of the United States capital markets under floating exchange rates. Akron Business Economy Review.v.12, p. 7-12, 1981.

AJAYI, R.A; MOUGOUÉ, M. On the dynamic relation between stock prices and exchange rates. Journal of Financial Research, 19, p. 193-207, 1996.

BAHMANI-OSKOOEE, M.; SOHRABIAN, A. Stock prices and the effective exchange rate of the dollar. Applied Economics, 24, p.459-464, 1992.

BRIGHAM, E. F.; EHRHARDT, M. C. Administração financeira: teoria e prática. São Paulo: Pioneira Thomson Learning, 2006

DICKEY, D.A.; FULLER, W.A. Distribution of the Estimators for Autoregressive Time Series with a Unit Root. Journal of the American Statistical Association, 74, p. 427-431, 1979.

ReFAE - Revista da Faculdade de Administração e Economia, v. 9, n. 2, p. 132-149, 2019 
GRANGER, C.; NEWBOLD, P. Spurious regressions in econometrics. Journal of Econometrics, Nottingham, v.2, p. 111-120, Jul. 1974.

IBRAHIM, H.; AZIZ, H. Macroeconomic variables and the malaysainequity market: a view through rolling subsamples. Journal of Economic Studies, 30(1), p.6-27, 2003.

KIM K. Dollar exchange rate and stock price: evidence from multivariate cointegration and error correction model. Review of Financial Economics, 12(3), p. 301-13, 2003.

KWIATKOWSKI, D.; PHILLIPS, P. C. B.; SCHMIDT, P.; Shin, Y. Testing the null hypothesis of stationarity against the alternative of a unit root. Journal of Econometrics, 54, p.159$178,1992$.

KOENKER, R; BASSET, G. Regression Quantiles. Econometrica. n. 46, 1978.

RATNER, M. A cointegration test of the impact of foreign exchange rates on U.S stock market prices. Global Finance Journal, 4(2), p. 93-101, 1993.

SAID, S.E.; DICKEY, D.A. Testing for Unit Roots in Autoregressive Moving Average Models of Unknown Order. Biometrika, 71, 599-607, 1984.

TABAK, B.M.; The dynamic relationship between stock prices and exchange rates: evidence from Brazil. Banco Central do Brasil - Working Paper Series, n. 124, p. 1-37, 2006.

TSAI, I-C. The relationship between stock price index and exchange rate in asian markets. Journal of International Financial Markets, Institutions \& Money, 22, p-609-621, 2012. 